\title{
Density functional studies of functionalized graphitic materials with late transition metals for oxygen reduction reactions
}

Vallejo, Federico Calle; Martinez, Jose Ignacio; RossmeisI, Jan

Published in:

Physical Chemistry Chemical Physics

Link to article, DOI:

$10.1039 / \mathrm{c} 1 \mathrm{cp} 21228 \mathrm{a}$

Publication date:

2011

Document Version

Publisher's PDF, also known as Version of record

Link back to DTU Orbit

Citation (APA):

Vallejo, F. C., Martinez, J. I., \& Rossmeisl, J. (2011). Density functional studies of functionalized graphitic materials with late transition metals for oxygen reduction reactions. Physical Chemistry Chemical Physics, 13(34), 15639-15643. https://doi.org/10.1039/c1cp21228a

\section{General rights}

Copyright and moral rights for the publications made accessible in the public portal are retained by the authors and/or other copyright owners and it is a condition of accessing publications that users recognise and abide by the legal requirements associated with these rights.

- Users may download and print one copy of any publication from the public portal for the purpose of private study or research.

- You may not further distribute the material or use it for any profit-making activity or commercial gain

- You may freely distribute the URL identifying the publication in the public portal 
Cite this: Phys. Chem. Chem. Phys., 2011, 13, 15639-15643

\title{
Density functional studies of functionalized graphitic materials with late transition metals for oxygen reduction reactions $\dagger$
}

\author{
Federico Calle-Vallejo, ${ }^{a b}$ José Ignacio Martínez $^{a c}$ and Jan Rossmeisl ${ }^{* a}$ \\ Received 18th April 2011, Accepted 11th July 2011 \\ DOI: $10.1039 / \mathrm{c} 1 \mathrm{cp} 21228 \mathrm{a}$
}

Low-temperature fuel cells are appealing alternatives to the conventional internal combustion engines for transportation applications. However, in order for them to be commercially viable, effective, stable and low-cost electrocatalysts are needed for the Oxygen Reduction Reaction (ORR) at the cathode. In this contribution, on the basis of Density Functional Theory (DFT) calculations, we show that graphitic materials with active sites composed of 4 nitrogen atoms and transition metal atoms belonging to groups 7 to 9 in the periodic table are active towards ORR, and also towards Oxygen Evolution Reaction (OER). Spin analyses suggest that the oxidation state of those elements in the active sites should in general be +2 . Moreover, our results verify that the adsorption behavior of transition metals is not intrinsic, since it can be severely altered by changes in the local geometry of the active site, the chemical nature of the nearest neighbors, and the oxidation states. Nonetheless, we find that these catalysts trend-wise behave as oxides and that their catalytic activity is limited by exactly the same universal scaling relations.

\section{Introduction}

In order for low-temperature fuel cells to be a commerciallyviable alternative to the conventional internal combustion engines for transportation applications, more effective, stable and low-cost catalysts are needed for the Oxygen Reduction Reaction (ORR), which takes place at the cathode and is known to be the main source of efficiency losses in these devices. ${ }^{1-4}$ Due to the limited world supply and the elevated cost of Pt, the material commonly used as ORR catalyst, the efforts in the field are mainly devoted to the development of two kinds of new electrocatalysts: (1) modified Pt with a higher specific activity than pure $\mathrm{Pt}^{5-9}$ and (2) inexpensive, stable and active cathode materials, such as perovskite oxides and carbon nanostructures. ${ }^{3,10-14}$ In both cases, the improvement of the current performance depends initially on a fundamental understanding of the particularities of ORR at the fuel cell conditions and secondly, on capitalizing the insight gained on the design of catalysts with targeted functionalities. Here we investigate graphitic materials on the basis of DFT calculations. These materials, in particular graphene, exhibit extraordinary thermal, mechanical and electro-optical properties. ${ }^{15-20}$

${ }^{a}$ Center for Atomic-scale Materials Design, Department of Physics,

Technical University of Denmark, DK-2800 Kgs. Lyngby, Denmark.

E-mail: jross@fysik.dtu.dk

${ }^{b}$ Leiden Institute of Chemistry, Leiden University, PO Box 9502,

NL-2300 RA Leiden, The Netherlands

${ }^{c}$ Departamento de Física Teórica de la Materia Condensada,

Universidad Autónoma de Madrid, ES-28049, Madrid, Spain

$\dagger$ Electronic supplementary information (ESI) available. See DOI:

$10.1039 / \mathrm{c} 1 \mathrm{cp} 21228 \mathrm{a}$
Furthermore, the N-functionalization of graphitic materials is interesting from a catalytic point of view due to the formation of stable sites that bind other types of ligands and can have multiple electronic, chemical, catalytic and mechanical applications. ${ }^{21-24}$ A step forward for the catalytic application of these materials was made by anchoring transition metals to active sites composed of pyridinic nitrogen atoms. Dodelet and co-workers have experimentally investigated catalysts based on $\mathrm{Fe}$ and $\mathrm{Co}$ attached to different nitrogen-modified carbon supports. ${ }^{10,25-28}$ They found that the active sites created in the interstices between graphitic crystallites in highly porous materials are particularly active towards ORR. Nitrogen atoms bond to the edges of adjacent crystallites forming pyridinic sites, where a $\mathrm{Fe}^{2+}$ cation is subsequently inserted. Besides, some other works have shown the catalytic activity of phthalocyanines, ${ }^{29,30}$ porphyrins, ${ }^{31}$ and enzymes, ${ }^{32}$ which have similar active sites, and also the possibility of using these active sites as supports for metallic nanoparticles. ${ }^{21}$

Following this idea, it seems particularly attractive to screen theoretically and developing experimentally carbon nanostructures functionalized with pyridinic nitrogen atoms and transition metals, for catalytic purposes. Computer simulations based on DFT make it possible to determine adsorption energies that can hence be used as ORR activity descriptors, ${ }^{33}$ predicted to determine the ORR and OER activity of materials, and lately confirmed..$^{5,34,35} \mathrm{We}$ have investigated the trends in the catalytic performance of graphitic layers with late transition metals anchored to pyridinic active sites towards the ORR, based on computational routines including calculation of the adsorption energies of the ORR intermediates $(* \mathrm{O}, * \mathrm{OH}, * \mathrm{OOH})$, and the scaling relations between them. ${ }^{36,37}$ 
The results reveal organized trends and allow for the identification of promising candidates through a Sabatier analysis. ${ }^{38}$

\section{Methods}

The DFT calculations of the ORR intermediates adsorbed on the top of the late transition metals anchored on functionalized graphitic layers with nitrogen were performed in the plane wave code DACAPO with the RPBE exchange-correlation functional. ${ }^{39}$ As shown in Fig. 1, two kinds of periodic rectangular unit cells with 1 active site per unit cell composed of 4 nitrogen atoms and a late transition metal atom were used. The ORR intermediates were adsorbed on the top of the transition metal atom. The vertical separation between successive slabs was in all cases more than $12 \AA$ and dipole corrections were applied. All atoms were free to move in all directions. The relaxations of the atoms were carried out with the quasi-Newton minimization scheme, until the maximum force on any atom was below $0.05 \mathrm{eV}^{-1}$.

Ionic cores were described by ultrasoft pseudopotentials. ${ }^{40}$ The Kohn-Sham one-electron states were expanded in a series of plane waves with an energy cutoff of $400 \mathrm{eV}$ and a density cutoff of $500 \mathrm{eV}$. The Brillouin zones of all systems were sampled with $3 \times 3 \times 1$ (Cell A in Fig. 1) and $4 \times 3 \times 1$ (Cell B in Fig. 2) Monkhorst-Pack grids. ${ }^{41}$ The self-consistent RPBE density was determined by iterative diagonalization of the Kohn-Sham Hamiltonian at an electronic temperature of $k_{\mathrm{B}} T=0.1 \mathrm{eV}$, using Pulay mixing of densities, and all total energies were extrapolated to $k_{\mathrm{B}} T=0 \mathrm{eV}$. Spin polarization effects were taken into account in all calculations.

The DFT adsorption energies of the ORR intermediates, $* \mathrm{O}, * \mathrm{OH}$, and $* \mathrm{OOH}$, were calculated relative to $\mathrm{H}_{2} \mathrm{O}(\mathrm{l})$ and $\mathrm{H}_{2}(\mathrm{~g})$, according to eqn (1) to (6):

$$
\begin{gathered}
\mathrm{GrM}+\mathrm{H}_{2} \mathrm{O}_{(\mathrm{l})} \leftrightarrow \mathrm{GrM}-\mathrm{O}+\mathrm{H}_{2(\mathrm{~g})} \\
\Delta E_{\mathrm{O}}=E_{\mathrm{GrM}-\mathrm{O}}-E_{\mathrm{GrM}}-\left(E_{\mathrm{H}_{2} \mathrm{O}}-E_{\mathrm{H}_{2}}\right) \\
\mathrm{GrM}+\mathrm{H}_{2} \mathrm{O}_{(\mathrm{l})} \leftrightarrow \mathrm{GrM}-\mathrm{OH}+\frac{1}{2} \mathrm{H}_{2(\mathrm{~g})} \\
\Delta E_{\mathrm{OH}}=E_{\mathrm{GrM}-\mathrm{OH}}-E_{\mathrm{GrM}}-\left(E_{\mathrm{H}_{2} \mathrm{O}}-\frac{1}{2} E_{\mathrm{H}_{2}}\right)
\end{gathered}
$$

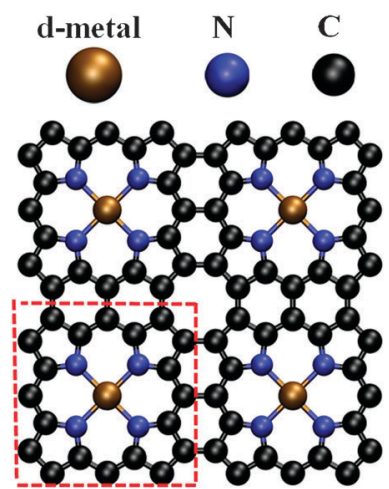

a) Cell $A$

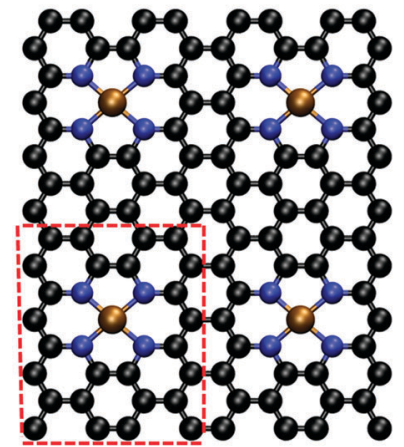

b) Cell B
Fig. $12 \times 2$ repetitions of the unit cells used in this study, (a) Cell A, with 3 carbon atoms between the nitrogen atoms in the active site, and (b) Cell $\mathrm{B}$, with alternating 2 and 3 carbon atoms between the nitrogen atoms in the active site. The unit cells are marked in red.
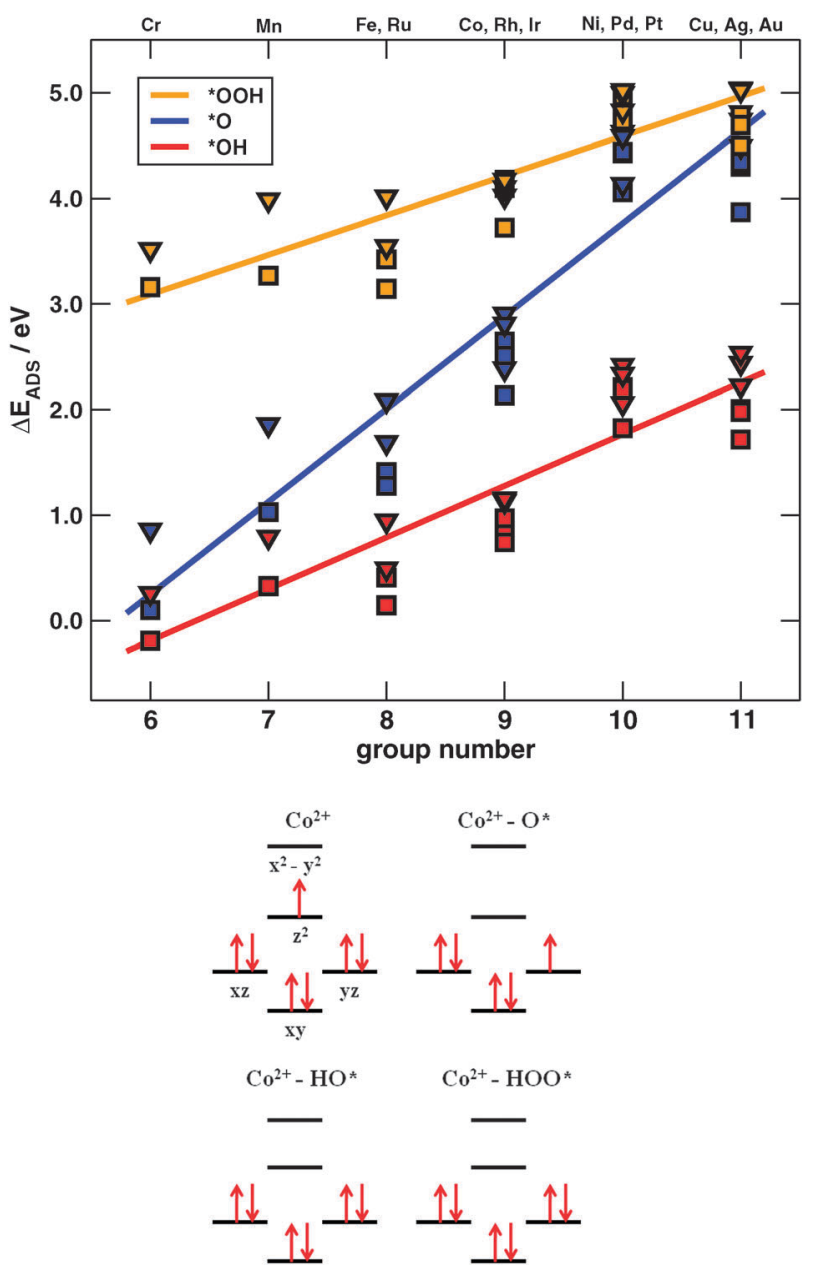

Fig. 2 Upper panel: Trends in adsorption energies of the ORR intermediates in graphitic materials with active sites composed of 4 nitrogen atoms and transition metals, for Cells A (triangles) and B (squares). Lines as guides to the eye have been drawn to show the trends and the constant separation of $\sim 3.10 \mathrm{eV}$ between the energy levels of $* \mathrm{OH}$ (red) and $* \mathrm{OOH}$ (yellow), and that of $* \mathrm{O}$ (blue) in between. In general, an increase in the number of d-electrons of the transition metals tends to decrease the strength of the interaction between the active site and the adsorbates. Lower panel: Band splitting for a $\mathrm{Co}^{2+}$ ion with 4 nitrogen atoms in a square planar orientation with and without ORR intermediates.

$$
\begin{gathered}
\mathrm{GrM}+2 \mathrm{H}_{2} \mathrm{O}_{(\mathrm{l})} \leftrightarrow \mathrm{GrM}-\mathrm{OOH}+\frac{3}{2} \mathrm{H}_{2(\mathrm{~g})} \\
\Delta E_{\mathrm{OOH}}=E_{\mathrm{GrM}-\mathrm{OOH}}-E_{\mathrm{GrM}}-\left(2 E_{\mathrm{H}_{2} \mathrm{O}}-\frac{3}{2} E_{\mathrm{H}_{2}}\right)
\end{gathered}
$$

Moreover, we assume the 4-electron ORR reaction path shown below in eqn (7) to (14). In each of the four steps, $\left(\mathrm{H}^{+}+\mathrm{e}^{-}\right)$react in order to transform successively one $\mathrm{O}_{2}$ molecule into two $\mathrm{H}_{2} \mathrm{O}$ molecules. We convert the calculated DFT adsorption energies $(\Delta E)$ into Gibbs free energies $(\Delta G)$ by adding entropic (TS) and zero-point energy corrections (ZPE) to the fluid phase molecules and ZPE corrections to adsorbed species as reported in ref. 38 and 42 (see ESI $\dagger$ ), so that $\Delta G_{\mathrm{O}}=$ $\Delta E_{\mathrm{O}}+0.05, \Delta G_{\mathrm{OH}}=\Delta E_{\mathrm{OH}}+0.35$, and $\Delta G_{\mathrm{OOH}}=\Delta E_{\mathrm{OOH}}+$ 0.40. Furthermore, we add a solvation correction to the ORR adsorbates which we have estimated as $\sim 0.30 \mathrm{eV}$. The correction accounts for the solvation of the $* \mathrm{OH}$ and $* \mathrm{OOH}$ adsorbed 
species by the solution surrounding the active site. The reason for this correction is the following: the enthalpy difference between the gas and liquid phases of water is $\sim 0.45 \mathrm{eV}$ at $298.15 \mathrm{~K}$ and 0.0317 bar, but their free energies are identical. ${ }^{43}$ The energetic difference comes from the presence of hydrogen bonds in the liquid phase, in which each $\mathrm{H}_{2} \mathrm{O}$ molecule creates $3 \mathrm{H}$-bonds (two as a donor and one as an acceptor) with adjacent molecules. Since $* \mathrm{OH}$ is able to create two $\mathrm{H}$-bonds, it will be stabilized by $\sim 0.30 \mathrm{eV}$ when solvated, and we expect $* \mathrm{OOH}$ to be stabilized in the same order of magnitude due to solvation effects.

$$
\begin{gathered}
\mathrm{O}_{2(\mathrm{~g})}+\left(\mathrm{H}^{+}+\mathrm{e}^{-}\right)+\mathrm{GrM} \leftrightarrow \mathrm{GrM}-\mathrm{OOH} \\
\Delta G_{4}=\left(\Delta G_{\mathrm{OOH}}-0.30\right)+2 \Delta G_{\mathrm{W}} \\
\mathrm{GrM}-\mathrm{OOH}+\left(\mathrm{H}^{+}+\mathrm{e}^{-}\right) \leftrightarrow \mathrm{GrM}-\mathrm{O}+\mathrm{H}_{2} \mathrm{O} \\
\Delta G_{3}=\Delta G_{\mathrm{O}}-\left(\Delta G_{\mathrm{OOH}}-0.30\right) \\
\mathrm{GrM}-\mathrm{O}+\left(\mathrm{H}^{+}+\mathrm{e}^{-}\right) \leftrightarrow \mathrm{GrM}-\mathrm{OH} \\
\Delta G_{2}=\left(\Delta G_{\mathrm{OH}}-0.30\right)-\Delta G_{\mathrm{O}} \\
\mathrm{GrM}-\mathrm{OH}+\left(\mathrm{H}^{+}+\mathrm{e}^{-}\right) \leftrightarrow \mathrm{GrM}-\mathrm{H}_{2} \mathrm{O} \\
\Delta G_{1}=-\left(\Delta G_{\mathrm{OH}}-0.30\right)
\end{gathered}
$$

The term $2 \Delta G_{\mathrm{W}}$ is equivalent to $-4.92 \mathrm{eV}$, i.e. twice the standard Gibbs energy of formation of water from $\mathrm{H}_{2}$ and $\frac{1}{2} \mathrm{O}_{2}$.

\section{Results and discussion}

The trends in adsorption energies of the ORR intermediates in graphitic materials with active sites composed of 4 nitrogen atoms and transition metals are shown in Fig. 2. Interestingly, we note that an increase in the number of d-electrons of the transition metals in the active sites tends to decrease the strength of the interaction between the active site and the adsorbates. This systematic behaviour is explained by taking into consideration the splitting of the d-band of the transition metal in this kind of complexes, shown in the right part of Fig. 2 for the specific case of Co. By means of similar spin analyses we can also address a fundamental matter: the oxidation states of the transition metals in the active sites (see ESI $\dagger$ ). Table 1 contains the possible oxidation states of the transition metals considered in this study, which we will discuss in detail below.

On the other hand, we observe in Fig. 2 a constant separation of $\sim 3.10 \mathrm{eV}$ between the energy levels of $* \mathrm{OH}$ and $* \mathrm{OOH}$, while that of ${ }^{*} \mathrm{O}$ moves in between those two. This is in agreement with previous analyses carried out on oxide surfaces which concluded that the energy levels of *OH and $* \mathrm{OOH}$ have a constant separation of $3.2 \pm 0.2 \mathrm{eV}$ on a wide range of oxide surfaces and metals. ${ }^{11,44}$ This constant separation has been attributed to the similarities between ${ }^{*} \mathrm{OH}$ and *OOH, given that both adsorb on the same position and form a simple bond with the surface. In the following, we will dissect this energy difference of $3.1 \mathrm{eV}$. When combining eqn (4) and (6), and converting into Gibbs energies, one can derive the following expression:

$$
\begin{aligned}
\Delta G_{\mathrm{OOH}}= & \Delta G_{\mathrm{OH}}+\left(G_{\mathrm{GrM}-\mathrm{OOH}}-G_{\mathrm{GrM}-\mathrm{OH}}\right) \\
& -\left(G_{\mathrm{H}_{2} \mathrm{O}}-G_{\mathrm{H}_{2}}\right)
\end{aligned}
$$

Table 1 Oxidation states of the transition metals in the active sites based on the spin analysis shown in Fig. 1 and in the ESI. $\dagger$ In the cases where 2 oxidation states render identical spin numbers, we report both of them

\begin{tabular}{lcl}
\hline Element in the active site & Group number & Oxidation state(s) \\
\hline $\mathrm{Cr}$ & 6 & +2 \\
$\mathrm{Mn}$ & 7 & +2 or +4 \\
$\mathrm{Fe}$ & 8 & +2 \\
$\mathrm{Ru}$ & 8 & +3 \\
$\mathrm{Co}$ & 9 & +2 \\
$\mathrm{Rh}$ & 9 & +2 \\
$\mathrm{Ir}$ & 9 & +2 \\
$\mathrm{Ni}$ & 10 & +2 \\
$\mathrm{Pd}$ & 10 & +2 \\
$\mathrm{Pt}$ & 10 & +2 \\
$\mathrm{Cu}$ & 11 & +2 \\
$\mathrm{Ag}$ & 11 & +1 \\
$\mathrm{Au}$ & 11 & +1 or +3 \\
\hline
\end{tabular}

According to our correlations, $\left(G_{\mathrm{GrM}-\mathrm{OOH}}-G_{\mathrm{GrM}-\mathrm{OH}}\right)-$ $\left(G_{\mathrm{H}_{2} \mathrm{O}}-G_{\mathrm{H}_{2}}\right)$ should be approximately $3.15 \mathrm{eV}$ (see Fig. 3 ). The extra $0.05 \mathrm{eV}$ comes from the $\mathrm{ZPE}$ and entropy corrections used. Moreover, the term $\left(G_{\mathrm{H}_{2} \mathrm{O}}-G_{\mathrm{H}_{2}}\right)$ is equivalent to $\left(\Delta G_{\mathrm{W}}+1 / 2 G_{\mathrm{O}_{2}}\right)$. Thus, eqn (15) transforms into the following:

$$
\begin{aligned}
\Delta G_{\mathrm{OOH}}= & \Delta G_{\mathrm{OH}}-\Delta G_{\mathrm{W}} \\
& +\left(G_{\mathrm{GrM}-\mathrm{OOH}}-G_{\mathrm{GrM}-\mathrm{OH}}-\frac{1}{2} G_{\mathrm{O}_{2}}\right)
\end{aligned}
$$

According to eqn (16), the total $3.15 \mathrm{eV}$ of separation can be divided into $2.46 \mathrm{eV}\left(-\Delta G_{\mathrm{W}}\right)$ coming from the thermochemical limitations of the system, and $0.69 \mathrm{eV}$ coming from the surface. One can, in principle, capitalize on these findings to reduce the overpotential in fuel cells or electrolyzers: the term in parenthesis in eqn (16) shows that if one stabilizes the $* \mathrm{OOH}$ level with respect to that of $* \mathrm{OH}$, e.g. creating additional interactions in $3 \mathrm{D}$ sites instead of $2 \mathrm{D}$ surface sites, the overpotential can be effectively reduced.

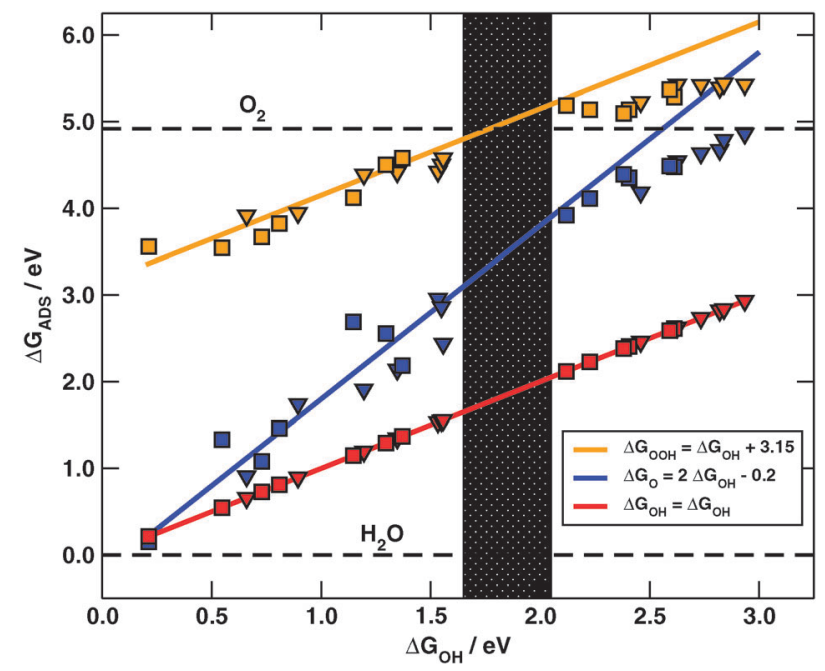

Fig. 3 Scaling relations between the adsorption energies of the ORR adsorbates. Blue: ${ }^{*} \mathrm{O} v s .{ }^{*} \mathrm{OH}$; yellow: ${ }^{*} \mathrm{OOH}$ vs. ${ }^{*} \mathrm{OH}$; red: ${ }^{*} \mathrm{OH}$ vs. ${ }^{*} \mathrm{OH}$, for Cells A (triangles) and B (squares). Horizontal lines for water and oxygen have been drawn at $0 \mathrm{eV}$ and $4.92 \mathrm{eV}$, respectively. The dotted area separates active sites with metals from groups 9 and before (to the left) from those in groups 10 and 11 (to the right). The position of the different transition metals along the lines is given by their number of d-electrons. 
In Fig. 3 we present the scaling relations between the Gibbs energies of adsorption of the ORR intermediates, as a function of $\Delta G_{\mathrm{OH}}$. We note again that the positions of the different transition metals along the lines are given by their number of d-electrons. Furthermore, we observe gaps of $\sim 1 \mathrm{eV}$ in the $* \mathrm{O}$ adsorption energies and $\sim 0.5 \mathrm{eV}$ in the $* \mathrm{OH}$ and $* \mathrm{OOH}$ adsorption energies in the 3 lines in Fig. 3. As a guide to the eye, we marked a dotted area between 1.6 and $2.1 \mathrm{eV}$ in the $x$-axis of Fig. 3 which includes the gaps in the 3 lines. This area strictly separates active sites with metals belonging to groups 9 and before, from those in groups 10 and 11. This evidences the antibonding nature of the $\mathrm{d}$ orbitals in these complexes and the discrete energetic leaps implied in their filling. On the other hand, we fixed the slopes of the lines $* \mathrm{O}$ $v s .{ }^{*} \mathrm{OH}$ (blue) and ${ }^{*} \mathrm{OOH} v s .{ }^{*} \mathrm{OH}$ (yellow) in Fig. 3 to be 2, the value expected from the scaling-relationships analysis and known to work for metals and oxides. ${ }^{36,37}$ These equations were also used as the input to construct the volcano plot in Fig. 4, by means of eqn (7) to (14). We note that both the scaling relations and the resulting volcanoes are similar to the results obtained for oxides. ${ }^{11,38}$ This similarity is expected since the linear scaling relations are determined by the number of bonds between the intermediate and the catalytic site, which in turn gives the slope of the scaling relation. Furthermore, the intercept of these relations seems to be determined by the geometry of the binding site. In this particular case, as on several oxides, ${ }^{11}$ all intermediates have only atop binding available, resulting in similar scaling relations. Therefore, from our calculations we cannot identify any reason why these materials should be more electrocatalytically active than oxides, which may be easier to synthesize. Nevertheless, graphitic materials are probably more stable in acidic environments and

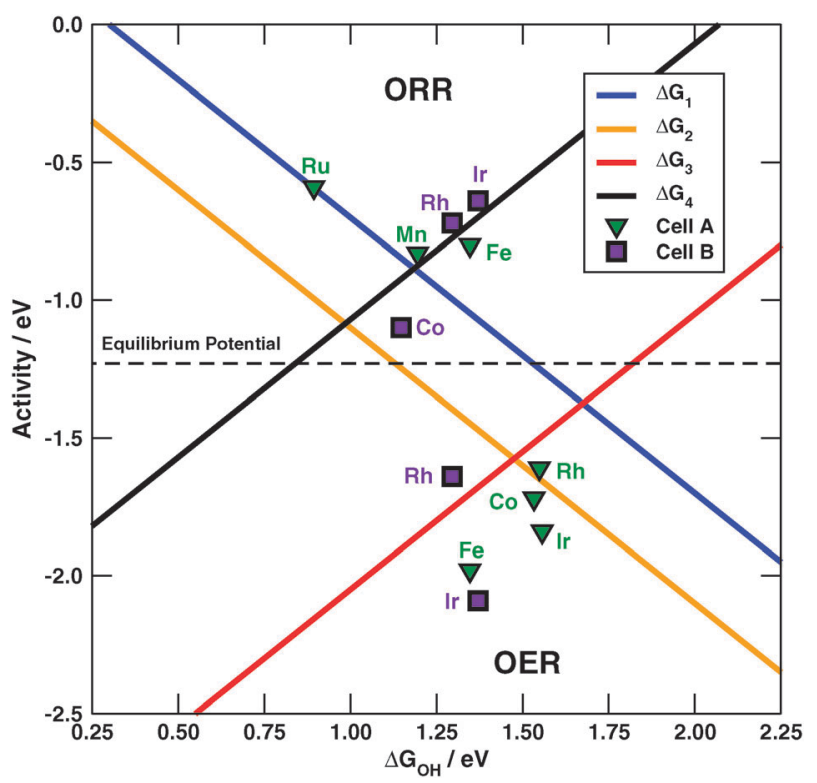

Fig. 4 Combined volcano plot for the ORR (up) and OER (below), resulting from the thermodynamic analysis shown in the main text. Only the most active metals in cells A (green) and B (purple) are shown. The lowest ORR overpotentials are achieved by active sites containing Fe, Ir, Mn and Rh, whereas the lowest OER overpotentials are achieved by active sites of $\mathrm{Co}, \mathrm{Rh}, \mathrm{Ir}$, and $\mathrm{Fe}$. in general more conductive than oxides, which in the end will be very important properties. Moreover, the fact that experimentally the active sites are formed in the interstices between graphitic layers in porous materials could, in principle, facilitate the aforementioned 3D interactions, and improve the ORR/ OER activities.

The volcano plot in Fig. 4 contains the lines representing the Gibbs free energies of each step in the mechanism, and the tops for ORR (at $\sim 1.2 \mathrm{eV}$ ) and OER (at $\sim 1.5 \mathrm{eV}$ ) result from the intersection of those lines. We remark that in Fig. 4 we have only marked the active sites with the highest activities for ORR and OER. We found that the former will be efficiently catalyzed by sites with $\mathrm{Fe}, \mathrm{Ir}, \mathrm{Mn}, \mathrm{Ru}$, and Rh; while the latter will be catalyzed by active sites of $\mathrm{Co}, \mathrm{Rh}$, and Ir. Our findings on graphitic materials with sites composed of $\mathrm{Fe}$ are in agreement with previous experimental results. ${ }^{10,26}$ Moreover, the insight given by DFT goes beyond to pinpoint sites with elements belonging to groups 7 to 9 in the periodic table as active materials towards ORR and OER. These elements have appropriate adsorption properties to catalyze these reactions on the basis of the following analysis. We find two limiting cases in Fig. 2 and 3. (1) When the *O level equals that of $* \mathrm{OH}$, i.e. for active sites to the left of Fig. 2 and 3, the stability of the $* \mathrm{OOH}$ intermediate is limited by the $\mathrm{O}-\mathrm{O}$ bond strength, which will tend to decompose into tightly bound $* \mathrm{O}$ and free $\mathrm{OH}$. This extreme is not convenient due to the exaggerated $* \mathrm{O}$ adsorption energy which will block the active site, preventing further advance of the reaction. (2) When the *O level equals that of $* \mathrm{OOH}$, i.e. to the right of Fig. 2 and 3, the stability of the $* \mathrm{OOH}$ intermediate will be limited by the $\mathrm{M}-\mathrm{O}$ bond strength and $* \mathrm{OOH}$ will then be loosely bound to the surface or will not stick to it at all. This extreme is also inconvenient due to the weak binding of $* \mathrm{OOH}$, which is the first intermediate of the ORR. Therefore, as suggested by Fig. 2 and 3 and supported by Fig. 4, the optimal ORR and OER catalysts belong to groups 7 to 9 , since they have a good compromise between the $\mathrm{M}-\mathrm{O}$ and $\mathrm{O}-\mathrm{O}$ bond strengths, so that the $* \mathrm{O}$ level is adequately placed in between those of $* \mathrm{OH}$ and $* \mathrm{OOH}$. In this respect, active sites composed of $\mathrm{Ir}$ seem particularly interesting, since they seem to be active both for ORR and OER. This alternative is worth trying experimentally, especially since Ir porphyrins and phthalocyanines have been used before for ORR ${ }^{45,46}$ Furthermore, we observe that the most active sites have commonly the oxidation state +2 . From a chemical point of view this is important, since it shows the role that the coordination and oxidation state play in the activity of determined species towards certain reaction. For instance, noble metals like $\mathrm{Pt}$ or $\mathrm{Pd}$, which have null oxidation states in metal phase, are the most active towards ORR, whereas in the graphitic environment considered here, having a different coordination and oxidation state, tends to bind too weakly. On the other hand Fe, normally seen as a reactive metal, displays high activity in this graphitic environment. We remark here that, as in the case of pure metals, the range of active elements is not large, but in graphitic materials the most promising candidates contain more non-noble options. This is why these materials are appealing for conducting these reactions in technological applications, once their current limitations are solved. ${ }^{10,26}$ 


\section{Conclusions}

We have shown that graphitic materials with active sites composed of 4 pyridinic nitrogen atoms and transition metals belonging to groups 7 to 9 in the periodic table are active towards ORR, and also towards OER. On the basis of spin analyses we observe that the oxidation state of those elements in the active sites should in general be +2 . Moreover, our results show that transition metals do not have intrinsic catalytic activities, since their adsorption behaviour can be severely altered by changes in the local geometry of the active site, the chemical nature of the nearest neighbours, and the oxidation states. Trend-wise speaking, these systems behave similarly to oxides. The scaling relations are close to those reported for oxides and the trends in ORR and OER catalysis are therefore also similar to oxides. Moreover, the catalytic performance of both can be improved by stabilizing the adsorption energy of $* \mathrm{OOH}$ with respect to that of $* \mathrm{OH}$, which can be done by carefully engineering the active sites.

\section{Acknowledgements}

CAMD is funded by the Lundbeck foundation. F.C.V. acknowledges support from the Danish Council for Strategic Research, via the SERC project, through grant no. 2104-06-0011, and the Danish Center for Scientific Computing through grant no. HDW-1103-06. J.I.M. acknowledges funding from Spanish MICINN through a Juan de la Cierva fellowship program. Drs Juan María García-Lastra and Francisco José Pérez-Alonso are kindly acknowledged for their help in this study.

\section{Notes and references}

1 J. O. Bockris and T. N. Veziroglu, Int. J. Hydrogen Energy, 2007, 32, 1605-1610.

2 H. A. Gasteiger, S. S. Kocha, B. Sompalli and F. T. Wagner, Appl. Catal., B, 2005, 56, 9-35.

3 H. A. Gasteiger and N. M. Markovic, Science, 2009, 324, 48-49.

4 B. C. H. Steele and A. Heinzel, Nature, 2001, 414, 345-352.

5 J. Greeley, I. E. L. Stephens, A. S. Bondarenko, T. P. Johansson, H. A. Hansen, T. F. Jaramillo, J. Rossmeisl, I. Chorkendorff and J. K. Norskov, Nat. Chem., 2009, 1, 552-556.

6 V. Stamenkovic, B. S. Mun, K. J. J. Mayrhofer, P. N. Ross, N. M. Markovic, J. Rossmeisl, J. Greeley and J. K. Norskov, Angew. Chem., Int. Ed., 2006, 45, 2897-2901.

7 V. R. Stamenkovic, B. Fowler, B. S. Mun, G. F. Wang, P. N. Ross, C. A. Lucas and N. M. Markovic, Science, 2007, 315, 493-497.

8 P. Strasser, S. Koh, T. Anniyev, J. Greeley, K. More, C. F. Yu, Z. C. Liu, S. Kaya, D. Nordlund, H. Ogasawara, M. F. Toney and A. Nilsson, Nat. Chem., 2010, 2, 454-460.

9 I. E. L. Stephens, A. S. Bondarenko, F. J. Perez-Alonso, F. CalleVallejo, L. Bech, T. P. Johansson, A. K. Jepsen, R. Frydendal, B. P. Knudsen, J. Rossmeisl and I. Chorkendorff, J. Am. Chem. Soc., 2011, 133, 5485-5491.

10 M. Lefevre, E. Proietti, F. Jaouen and J. P. Dodelet, Science, 2009, 324, 71-74.

11 I. C. Man, H.-Y. Su, F. Calle-Vallejo, H. A. Hansen, J. I. Martinez, N. G. Inoglu, J. R. Kitchin, T. F. Jaramillo, J. K. Norskov and J. Rossmeisl, ChemCatChem, 2011, 3, 1159-1165.
12 J. Suntivich, H. A. Gasteiger, N. Yabuuchi and Y. Shao-Horn, J. Electrochem. Soc., 2010, 157, B1263-B1268.

13 D. Thiele and A. Zuttel, J. Power Sources, 2008, 183, 590-594.

14 F. Calle-Vallejo, J. I. Martinez, J. M. Garcia-Lastra, M. Mogensen and J. Rossmeisl, Angew. Chem., Int. Ed., 2010, 49, 7699-7701.

15 M. J. Allen, V. C. Tung and R. B. Kaner, Chem. Rev., 2010, 110, 132-145.

16 A. H. Castro Neto, F. Guinea, N. M. R. Peres, K. S. Novoselov and A. K. Geim, Rev. Mod. Phys., 2009, 81, 109-162.

17 A. K. Geim and K. S. Novoselov, Nat. Mater., 2007, 6, 183-191.

18 K. S. Novoselov, A. K. Geim, S. V. Morozov, D. Jiang, Y. Zhang, S. V. Dubonos, I. V. Grigorieva and A. A. Firsov, Science, 2004, 306, 666-669.

19 N. M. R. Peres, J. Phys.: Condens. Matter, 2009, 21, 344202.

20 J. S. Wu, W. Pisula and K. Mullen, Chem. Rev., 2007, 107, 718-747.

21 G. Kim and S. H. Jhi, ACS Nano, 2011, 5, 805-810.

22 K. A. Kurak and A. B. Anderson, J. Phys. Chem. C, 2009, 113, 6730-6734.

23 S. R. Stoyanov, A. V. Titov and P. Kral, Coord. Chem. Rev., 2009, 253, 2852-2871.

24 E. Vayner and A. B. Anderson, J. Phys. Chem. C, 2007, 111, $9330-9336$.

25 F. Jaouen, F. Charreteur and J. P. Dodelet, J. Electrochem. Soc., 2006, 153, A689-A698.

26 F. Jaouen, E. Proietti, M. Lefevre, R. Chenitz, J. P. Dodelet, G. Wu, H. T. Chung, C. M. Johnston and P. Zelenay, Energy Environ. Sci., 2011, 4, 114-130.

27 M. Lefevre and J. P. Dodelet, Electrochim. Acta, 2003, 48, 2749-2760.

28 C. Medard, M. Lefevre, J. P. Dodelet, F. Jaouen and G. Lindbergh, Electrochim. Acta, 2006, 51, 3202-3213.

29 R. R. Chen, H. X. Li, D. Chu and G. F. Wang, J. Phys. Chem. C, 2009, 113, 20689-20697.

30 J. H. Zagal, Coord. Chem. Rev., 1992, 119, 89-136.

31 Y. Kiros, Int. J. Electrochem. Sci., 2007, 2, 285-300.

32 C. H. Kjaergaard, J. Rossmeisl and J. K. Norskov, Inorg. Chem., 2010, 49, 3567-3572.

33 J. K. Norskov, T. Bligaard, J. Rossmeisl and C. H. Christensen, Nat. Chem., 2009, 1, 37-46.

34 J. O. Bockris and T. Otagawa, J. Electrochem. Soc., 1984, 131, 290-302.

35 P. Ruetschi and P. Delahay, J. Chem. Phys., 1955, 23, 556-560.

36 F. Abild-Pedersen, J. Greeley, F. Studt, J. Rossmeisl, T. R. Munter, P. G. Moses, E. Skulason, T. Bligaard and J. K. Norskov, Phys. Rev. Lett., 2007, 99, 016105.

37 E. M. Fernandez, P. G. Moses, A. Toftelund, H. A. Hansen, J. I. Martinez, F. Abild-Pedersen, J. Kleis, B. Hinnemann, J. Rossmeisl, T. Bligaard and J. K. Norskov, Angew. Chem., Int. Ed., 2008, 47, 4683-4686.

38 J. Rossmeisl, Z. W. Qu, H. Zhu, G. J. Kroes and J. K. Norskov, J. Electroanal. Chem., 2007, 607, 83-89.

39 B. Hammer, L. B. Hansen and J. K. Norskov, Phys. Rev. B. Condens. Matter, 1999, 59, 7413-7421.

40 D. Vanderbilt, Phys. Rev. B: Condens. Matter, 1990, 41, 7892-7895.

41 D. J. Chadi and M. L. Cohen, Phys. Rev. B: Solid State, 1973, 8, $5747-5753$.

42 J. K. Norskov, J. Rossmeisl, A. Logadottir, L. Lindqvist, J. R. Kitchin, T. Bligaard and H. Jonsson, J. Phys. Chem. B, 2004, 108, 17886-17892.

43 D. R. Lide, CRC Handbook of Chemistry and Physics, CRC Press/ Taylor and Francis, Boca Raton, FL, 90th edn, CD-ROM version, 2010.

44 J. Rossmeisl, A. Logadottir and J. K. Norskov, Chem. Phys., 2005, 319, 178-184.

45 A. L. Bouwkampwijnoltz, W. Visscher and J. A. R. Vanveen, Electrochim. Acta, 1994, 39, 1641-1645.

46 J. P. Collman, L. L. Chng and D. A. Tyvoll, Inorg. Chem., 1995, 34, 1311-1324. 